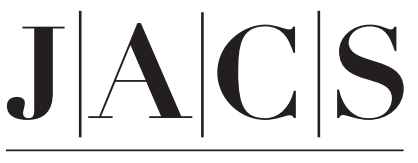

A R T I C L E S

Published on Web 10/19/2004

\title{
Envisaging the Physicochemical Processes during the Preparation of Supported Catalysts: Raman Microscopy on the Impregnation of Mo onto $\mathrm{Al}_{2} \mathrm{O}_{3}$ Extrudates
}

\author{
Jaap A. Bergwerff, ${ }^{\dagger}$ Tom Visser, ${ }^{\dagger}$ Bob R. G. Leliveld, ${ }^{\ddagger}$ Brenda D. Rossenaar, $\$$ \\ Krijn P. de Jong, ${ }^{\dagger}$ and Bert M. Weckhuysen*, ${ }^{\star}$ \\ Contribution from the Department of Inorganic Chemistry and Catalysis, Debye Institute, \\ Utrecht University, Sorbonnelaan 163508 TB Utrecht, The Netherlands; Albermarle Catalysts \\ Company BV, Nieuwendammerkade 1-3 1022 AB Amsterdam, The Netherlands; and Akzo Nobel \\ Chemicals Research, Velperweg 766824 BM Arnhem, The Netherlands
}

Received April 12, 2004; E-mail: b.m.weckhuysen@chem.uu.nl

\begin{abstract}
Raman microscopy has been applied to study the preparation of shaped $\mathrm{Mo} / \mathrm{Al}_{2} \mathrm{O}_{3}$ catalysts. The speciation of different Mo complexes over $\gamma-\mathrm{Al}_{2} \mathrm{O}_{3}$ support bodies was followed in time after pore volume impregnation with aqueous solutions containing different $\mathrm{Mo}$ complexes. The addition of $\mathrm{NO}_{3}{ }^{-}$to the impregnation solutions allows for a quantitative Raman analysis of the distribution of different complexes over the catalyst bodies as this ion can be used as an internal standard. After impregnation with an acidic ammonium heptamolybdate $(\mathrm{AHM})$ solution, the strong interaction between $\mathrm{Mo}_{7} \mathrm{O}_{24}{ }^{6-}$ and $\mathrm{Al}_{2} \mathrm{O}_{3}$ results in slow transport of this complex through the support and extensive formation of $\mathrm{Al}(\mathrm{OH})_{6} \mathrm{Mo}_{6} \mathrm{O}_{18}{ }^{3-}$ near the outer surface of the support bodies. This may be prevented by decreasing the interaction between Mo and $\mathrm{Al}_{2} \mathrm{O}_{3}$. In this way, transport is facilitated and a homogeneous distribution of $\mathrm{Mo}$ is obtained on a reasonable time scale. A decrease in interaction between $\mathrm{Mo}$ and $\mathrm{Al}_{2} \mathrm{O}_{3}$ can be achieved by using alkaline impregnation solutions or by the addition of complexing agents, such as citrate and phosphate, to the impregnation solution. In general, time-resolved in situ Raman microscopy can be a valuable tool to study the physicochemical processes during the preparation of supported catalysts.
\end{abstract}

\section{Introduction}

Heterogeneous catalysts are of crucial importance for our present-day society and economy, as they find application in essential industrial processes such as oil refining, chemicals manufacturing, and environmental catalysis. The preparation of an efficient solid catalyst requires careful design at multiple length scales. ${ }^{1-5}$ For this reason, several authors have carried out in situ studies on the synthesis of solid catalyst systems. Especially the preparation of zeolites ${ }^{6-14}$ and mesoporous

$\dagger$ Utrecht University.

$\doteqdot$ Albermarle Catalysts Company BV.

$\S$ Akzo Nobel Chemicals Research.

(1) Ertl, G.; Knozinger, H.; Weitkamp, J. Preparation of Solid Catalysts; WileyVCH: Weinheim, 1999.

(2) Hagen, J. Industrial Catalysis: A Practical Approach; Wiley-VCH: Weinheim, 1999.

(3) De Jong, K. P. CATTECH 1998, 3, 87-95.

(4) De Jong, K. P. Curr. Opin. Solid State Mater. Sci. 1999, 4, 55-62.

(5) Schlogl, R.; Abd Hamid, S. B. Angew. Chem., Int. Ed. 2004, 43, $1628-$ 1637.

(6) Beitone, L.; Huguenard, C.; Gansmuller, A.; Henry, M.; Taulelle, F.; Loiseau, T.; Ferey, G. J. Am. Chem. Soc. 2003, 125, 9102-9110.

(7) Beitone, L.; Marrot, J.; Loiseau, T.; Ferey, G.; Henry, M.; Huguenard, C.; Gansmuller, A.; Taulelle, F. J. Am. Chem. Soc. 2003, 125, 1912-1922.

(8) De Moor, P.; Beelen, T. P. M.; Komanschek, B. U.; Beck, L. W.; Wagner, P.; Davis, M. E.; van Santen, R. A. Chem-Eur. J. 1999, 5, 2083-2088.

(9) De Moor, P.; Beelen, T. P. M.; van Santen, R. A. J. Phys. Chem. B 1999 $103,1639-1650$

(10) Francis, R. J.; O’Brien, S.; Fogg, A. M.; Halasyamani, P. S.; O’Hare, D.; Loiseau, T.; Ferey, G. J. Am. Chem. Soc. 1999, 121, 1002-1015.

(11) Taulelle, F.; Haouas, M.; Gerardin, C.; Estournes, C.; Loiseau, T.; Ferey, G. Colloids Surf., A 1999, 158, 299-311. materials ${ }^{15-19}$ has been studied in great detail using a variety of characterization techniques.

To obtain an efficient supported catalyst, metal(oxide) particles of sub-nanometer scale are to be deposited in a homogeneous fashion inside the pores of a support material, which are typically $10-100 \mathrm{~nm}$ wide. The catalyst material is often shaped into bodies of $1-3 \mathrm{~mm}$ to prevent a pressure drop in industrial reactors. Despite their complexity, these nanostructures are generally manufactured in a surprisingly straightforward manner. Pore volume impregnation of support bodies is carried with a solution containing a metal precursor, followed by aging and drying. Over the years, models have been developed to describe the physicochemical processes that take

(12) Sankar, G.; Thomas, J. M.; Rey, F.; Greaves, G. N. J. Chem. Soc., Chem. Commun. 1995, 2549-2550.

(13) Haouas, M.; Gerardin, C.; Taulelle, F.; Estournes, C.; Loiseau, T.; Ferey, G. J. Chim. Phys. Phys.-Chim. Biol. 1998, 95, 302-309.

(14) Weckhuysen, B. M.; Baetens, D.; Schoonheydt, R. A. Angew. Chem., Int Ed. 2000, 39, 3419-3422.

(15) Tolbert, S. H.; Firouzi, A.; Stucky, G. D.; Chmelka, B. F. Science 1997, 278, 264-268.

(16) O’Brien, S.; Francis, R. J.; Fogg, A.; O'Hare, D.; Okazaki, N.; Kuroda, K. Chem. Mater. 1999, 11, 1822-1832.

(17) Firouzi, A.; Kumar, D.; Bull, L. M.; Besier, T.; Sieger, P.; Huo, Q.; Walker, S. A.; Zasadzinski, J. A.; Glinka, C.; Nicol, J.; Margolese, D.; Stucky, G. D.; Chmelka, B. F. Science 1995, 267, 1138-1143.

(18) Galarneau, A.; Di Renzo, F.; Fajula, F.; Mollo, L.; Fubini, B.; Ottaviani, M. F. J. Colloid Interface Sci. 1998, 201, 105-117.

(19) Linden, M.; Schunk, S. A.; Schuth, F. Angew. Chem., Int. Ed. 1998, 37, 821-823.

10.1021/ja040107c CCC: $\$ 27.50$ @ 2004 American Chemical Society 
place during the preparation of supported catalyst bodies, ${ }^{20-27}$ but in all cases characterization was carried out after drying and/or calcination. Spectroscopic studies that focus on the interaction between metal precursors and the support have generally been carried out on powder supports. ${ }^{28-33}$

It is generally accepted that, after impregnation, imbibition of the water phase by the support is practically instantaneous due to the huge capillary suction created by its pore system. However, as a result of the interaction between the metal complexes in solution and the surface of the support, transport of the metal precursor can be much slower. ${ }^{21,22}$ It may take considerable time before a homogeneous distribution of the metal precursor over the support bodies is achieved and irreversible adsorption can even result in an eggshell distribution of the active phase. ${ }^{21,34-36}$ To allow for equilibration of the system, an aging step is therefore applied before drying in industrial catalyst preparation. In this study, this equilibration process after the impregnation of $\gamma-\mathrm{Al}_{2} \mathrm{O}_{3}$ support bodies with Mo-precursor solutions is followed using Raman microscopy.

$(\mathrm{Co}) \mathrm{MoS}_{2}$ and $(\mathrm{Ni}) \mathrm{MoS}_{2}$ on alumina catalysts are the key catalysts for the hydrotreating process, in which sulfur, nitrogen, and metals are removed from fuel streams. While the $\mathrm{MoS}_{2}$ is the active phase, cobalt and nickel act as a promoter in these systems. Catalyst manufacturers produce these catalysts by incipient wetness impregnation of $\gamma-\mathrm{Al}_{2} \mathrm{O}_{3}$ extrudates with a solution containing both the $\mathrm{Mo}$ and $\mathrm{Co} / \mathrm{Ni}$ precursors, followed by consecutive drying, calcination, and sulfidation steps. The activity of the final catalyst is strongly dependent on the nature of the $\mathrm{MoO}_{x}$ phase obtained after impregnation and hence on the properties of the impregnation solution. It is therefore not surprising that over the years a vast amount of research has been dedicated to the understanding of the interaction of aqueous

(20) Komiyama, M. Catal. Rev.-Sci. Eng. 1985, 27, 341-372.

(21) Lee, S. Y.; Aris, R. Catal. Rev.-Sci. Eng. 1985, 27, 207-340.

(22) De Jong, K. P. Stud. Surf. Sci. Catal. 1991, 63, 19-36.

(23) Okamoto, Y.; Arima, Y.; Nakai, K.; Umeno, S.; Katada, N.; Yoshida, H.; Tanaka, T.; Yamada, M.; Akai, Y.; Segawa, K.; Nishijima, A.; Matsumoto, H.; Niwa, M.; Uchijima, T. Appl. Catal., A 1998, 170, 315-328.

(24) Okamoto, Y.; Arima, Y.; Hagio, M.; Nakai, K.; Umeno, S.; Akai, Y.; Uchikawa, K.; Inamura, K.; Ushikubo, T.; Katada, N.; Hasegawa, S.; Yoshida, H.; Tanaka, T.; Isoda, T.; Mochida, I.; Segawa, K.; Nishijima, A.; Yamada, M.; Matsumoto, H.; Niwa, M.; Uchijima, T. Appl. Catal., A 1998, 170, 329-342.

(25) Okamoto, Y.; Umeno, S.; Arima, Y.; Nakai, K.; Takahashi, T.; Uchikawa, K.; Inamura, K.; Akai, Y.; Chiyoda, O.; Katada, N.; Shishido, T.; Hattori, H.; Hasegawa, S.; Yoshida, H.; Segawa, K.; Koizumi, N.; Yamada, M.; Nishijima, A.; Kabe, T.; Ishihara, A.; Isoda, T.; Mochida, I.; Matsumoto, H.; Niwa, M.; Uchijima, T. Appl. Catal., A 1998, 170, 343-357.

(26) Okamoto, Y.; Umeno, S.; Shiraki, Y.; Arima, Y.; Nakai, K.; Chiyoda, O.; Yoshida, H.; Uchikawa, K.; Inamura, K.; Akai, Y.; Hasegawa, S.; Shishido, T.; Hattori, H.; Katada, N.; Segawa, K.; Koizumi, N.; Yamada, M.; Mochida, I.; Ishihara, A.; Kabe, T.; Nishijima, A.; Matsumoto, H.; Niwa, M.; Uchijima, T. Appl. Catal. A-Gen. 1998, 170, 359-379.

(27) Santhanam, N.; Conforti, T. A.; Spieker, W.; Regalbuto, J. R. Catal. Today 1994, $21,141-156$

(28) Carrier, X.; Lambert, J. F.; Che, M. J. Am. Chem. Soc. 1997, 119, 1013710146.

(29) Carrier, X.; de la Caillerie, J. B. D.; Lambert, J. F.; Che, M. J. Am. Chem. Soc. 1999, 121, 3377-3381.

(30) Carriat, J. Y.; Che, M.; Kermarec, M.; Verdaguer, M.; Michalowicz, A. J. Am. Chem. Soc. 1998, 120, 2059-2070.

(31) Trouillet, L.; Toupance, T.; Villain, F.; Louis, C. Phys. Chem. Chem. Phys. 2000, 2, 2005-2014.

(32) Weckhuysen, B. M.; Wachs, I. E.; Schoonheydt, R. A. Chem. Rev. 1996, 96, 3327-3349.

(33) Weckhuysen, B. M. In-situ spectroscopy of catalysts; American Scientific Publishers: Stevenson Ranch, CA, 2004.

(34) Lekhal, A.; Glasser, B. J.; Khinast, J. G. Chem. Eng. Sci. 2001, 56, $4473-$ 4487.

(35) Lekhal, A.; Glasser, B. J.; Khinast, J. G. Chem. Eng. Sci. 2004, 59, $1063-$ 1077.

(36) Neimark, A. V.; Kheifez, L. I.; Fenelonov, V. B. Ind. Eng. Chem. Prod. Res. Dev. 1981, 20, 439-450.
Table 1. Chemical Composition and $\mathrm{pH}$ of the Impregnation Solutions Used for the Preparation of Supported Molybdenum Oxide Catalysts

\begin{tabular}{lccccc}
\hline \multicolumn{1}{c}{ name } & {$[\mathrm{Mo}](\mathrm{M})$} & {$[\mathrm{P}](\mathrm{M})$} & {$[$ citrate] $(\mathrm{M})$} & {$\left[\mathrm{NO}_{3}{ }^{-}\right](\mathrm{M})$} & $\mathrm{pH}$ \\
\hline Mo-pH5.2 & 1.00 & & & 0.66 & 5.2 \\
Mo-pH9.0 & 1.00 & & & 0.66 & 9.0 \\
Mo-citrate & 1.00 & & \multirow{2}{*}{1.00} & 0.66 & 0.5 \\
Mo-P(0.5) & 1.00 & 0.50 & & 0.66 & 2.0 \\
Mo-P(1.0) & 1.00 & 1.00 & & 0.66 & 2.0 \\
& & & & & \\
\hline
\end{tabular}

Mo complexes with $\mathrm{Al}_{2} \mathrm{O}_{3}$ surfaces. ${ }^{28,37-46}$ Raman spectroscopy is a powerful method to monitor the nature of the Mo complexes in both the impregnation solution and in wet, dried, and calcined catalysts and has therefore found extensive application in this field of research. ${ }^{37,38,40-42,47-51}$

In this work, the first application of Raman microscopy to monitor the physicochemical processes during the preparation of supported catalysts is presented. The methodology has been explored for the impregnation of $\mathrm{Al}_{2} \mathrm{O}_{3}$ pellets with solutions containing different $\mathrm{Mo}^{6+}$ complexes but is applicable to many supported metal catalyst systems. By making cross-sectional scans, Raman spectra are recorded at different positions inside the individual catalyst bodies. This procedure can be repeated at several points in time after impregnation, which allows one to monitor the transport and formation of different Mo complexes in the pore system of the support as a function of time. Mapping of the different Mo complexes as a function of place and time can be obtained. Impregnation is carried out using Mo solutions of different $\mathrm{pH}$, enabling the study of the interaction between the $\mathrm{MoO}_{4}{ }^{2-}$ and $\mathrm{Mo}_{7} \mathrm{O}_{24}{ }^{6-}$ anions and the $\mathrm{Al}_{2} \mathrm{O}_{3}$ support. Furthermore, the effect of complexing agents, such as citrate and phosphate, has been investigated.

\section{Experimental Section}

Cylindrical $\gamma-\mathrm{Al}_{2} \mathrm{O}_{3}$ pellets (Engelhard) were calcined at $600{ }^{\circ} \mathrm{C}$ for $6 \mathrm{~h}$ and stored at $120^{\circ} \mathrm{C}$ before impregnation. The pore volume of the support was $1.1 \mathrm{~mL} / \mathrm{g}$, while its surface area was $200 \mathrm{~m}^{2} / \mathrm{g}$. The pellets were $3 \mathrm{~mm}$ in both length and diameter. The point of zero charge (PZC) of the $\gamma-\mathrm{Al}_{2} \mathrm{O}_{3}$ was determined to be between 8.8 and 9.0 by potentiometric mass titrations. ${ }^{52}$ Pore volume impregnation was carried out using $1 \mathrm{M}$ Mo solutions, yielding a 15 -wt $\% \mathrm{MoO}_{3}$ loading in the final catalyst. Care was taken that the impregnation solution was homogeneously distributed over all particles by rotating the impregnation vessel continuously. After impregnation, the support bodies were kept in a closed vessel to prevent evaporation of water. At several points in time after impregnation, pellets were cleaved in the middle, perpendicular to their axis, using a razor blade. Raman spectra were

(37) Knözinger, H.; Jeziorowski, H. J. Phys. Chem. 1978, 82, 2002-2005.

(38) Jeziorowski, H.; Knözinger, H.; Grange, P.; Gajardo, P. J. Phys. Chem 1980, 84, 1825-1829.

(39) Grimblot, J. Catal. Today 1998, 41, 111-128.

(40) Mestl, G.; Srinivasan, T. K. K. Catal. Rev.-Sci. Eng. 1998, 40, 451-570.

(41) Jeziorowski, H.; Knözinger, H. J. Phys. Chem. 1979, 83, 1166-1173.

(42) Wang, L.; Hall, W. K. J. Catal. 1980, 66, 251-255.

(43) Carrier, X.; Lambert, J. F.; Kuba, S.; Knozinger, H.; Che, M. J. Mol. Struct. 2003, 656, 231-238

(44) Cheng, W. C.; Luthra, N. P. J. Catal. 1988, 109, 163-169.

(45) Van Veen, J. A. R.; Hendriks, P.; Romers, E.; Andrea, R. R. J. Phys. Chem. 1990, 94, 5275-5282.

(46) Van Veen, J. A. R.; Hendriks, P.; Andrea, R. R.; Romers, E.; Wilson, A E. J. Phys. Chem. 1990, 94, 5282-5285.

(47) Deo, G.; Wachs, I. E. J. Phys. Chem. 1991, 95, 5889-5895.

(48) Banares, M. A.; Wachs, I. E. J. Raman Spectrosc. 2002, 33, 359-380

(49) Wachs, I. E. Catal. Today 1996, 27, 437-455.

(50) Chen, K.; Xie, S.; Bell, A. T.; Iglesia, E. J. Catal. 2001, 198, 232-242.

(51) Le Bihan, L.; Blanchard, P.; Fournier, M.; Grimblot, J.; Payen, E. J. Chem. Soc., Faraday Trans. 1998, 94, 937-940.

(52) Vakros, J.; Kordulis, C.; Lycourghiotis, A. Chem. Commun. 2002, 19801981 

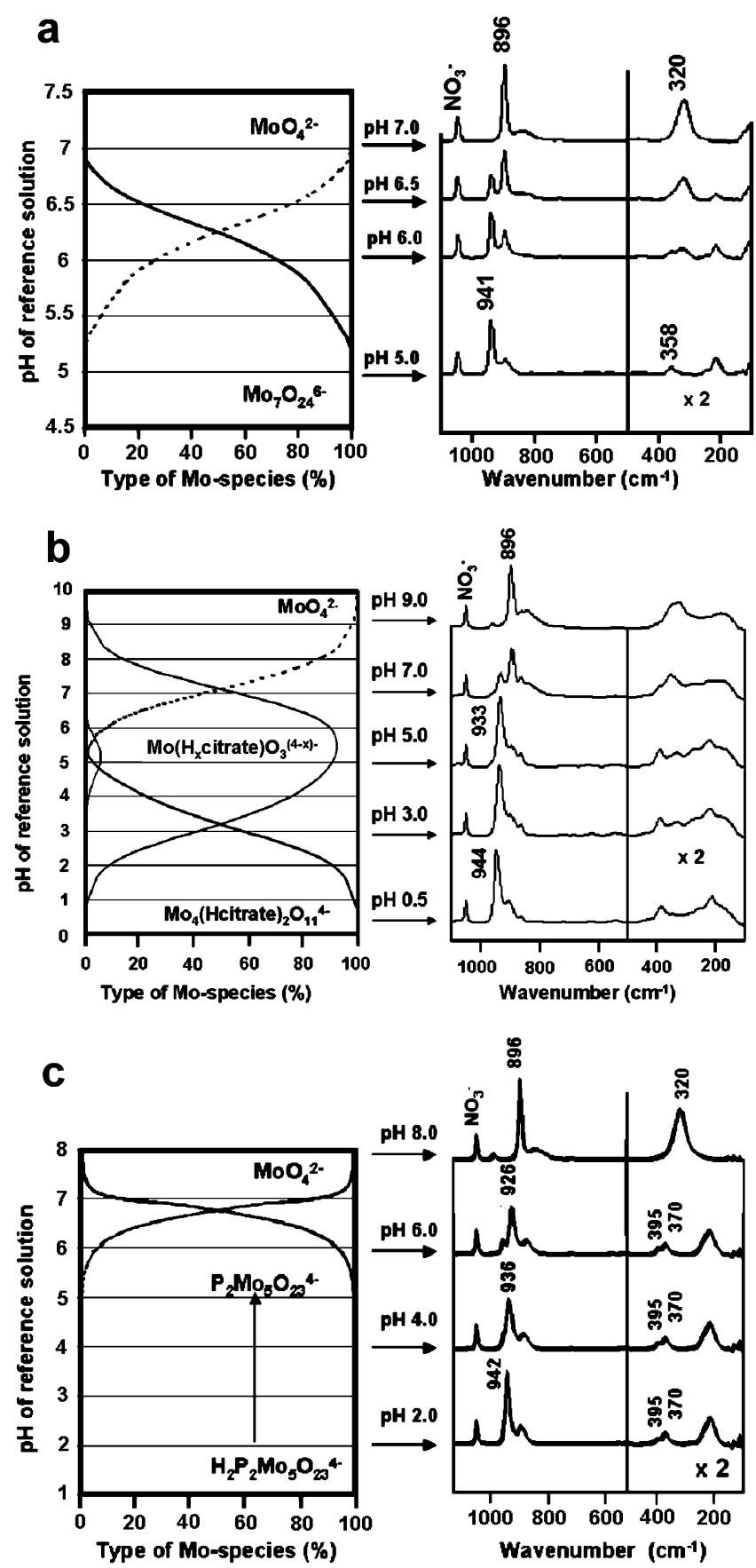

Figure 1. Calculated composition of the impregnation solutions used for the preparation of supported molybdenum oxide catalysts as a function of the $\mathrm{pH}$, and corresponding Raman spectra: (a) $1 \mathrm{M}$ Mo solution, (b) $1 \mathrm{M}$ Mo, $1 \mathrm{M}$ citrate solution, (c) $1 \mathrm{M} \mathrm{Mo,} 0.5 \mathrm{M} \mathrm{PO}_{4}{ }^{3-}$ solution. The Raman peaks are labeled as well as the reference $\mathrm{NO}_{3}{ }^{-}$peak located at $1048 \mathrm{~cm}^{-1}$.

recorded on the surface of the resulting cross sections. A Kaiser RXN spectrometer equipped with a $785 \mathrm{~nm}$ diode laser was used in combination with a Hololab 5000 Raman microscope. A 10× objective was used for beam focusing and collection of scattered radiation, resulting in a spot size on the sample of approximately $50 \mu \mathrm{m}$. The laser output power was $70 \mathrm{~mW}$. When recording a series of measurements at the same spot on the sample, identical spectra were found, indicating that no damage was done, by, e.g., laser radiation, to the sample during measurements. For a typical measurement, five spectra were accumulated with a $3 \mathrm{~s}$ exposure time. Background correction was carried out by subtraction of a reference spectrum recorded on wet $\mathrm{Al}_{2} \mathrm{O}_{3}$.
Table 2. Characteristic Vibrations $\left(\mathrm{cm}^{-1}\right)$ of Mo Complexes Present in the Solutions under Study

\begin{tabular}{|c|c|c|c|c|c|c|c|c|}
\hline composition & $\mathrm{pH}$ & species & & $v\left(\mathrm{MoO}_{2}\right.$ & & \multicolumn{3}{|c|}{$\delta\left(\mathrm{MoO}_{2 \mathrm{t}}\right)$} \\
\hline \multirow[t]{2}{*}{ AHM } & 8.0 & $\mathrm{MoO}_{4}^{2-}$ & 896 & 836 & & 320 & & \\
\hline & 5.5 & $\mathrm{Mo}_{7} \mathrm{O}_{24}{ }^{6-}$ & 941 & 896 & & 358 & & \\
\hline \multirow[t]{2}{*}{ Mo-citrate $1: 1$} & 0.5 & $\mathrm{Mo}_{4}(\text { Hcitrate })_{2} \mathrm{O}_{11}^{4-}$ & 944 & 901 & 861 & 385 & 373 & 343 \\
\hline & 4.0 & $\mathrm{Mo}\left(\mathrm{H}_{x}\right.$ citrate $) \mathrm{O}_{3}(4-x)-$ & 933 & 901 & 861 & 385 & & \\
\hline \multirow[t]{3}{*}{ Мо-P 2:1 } & 6.0 & $\mathrm{P}_{2} \mathrm{Mo}_{5} \mathrm{O}_{23}{ }^{6-}$ & 956 & 926 & 874 & 395 & 370 & \\
\hline & 4.0 & $\mathrm{H}_{x} \mathrm{P}_{2} \mathrm{Mo}_{5} \mathrm{O}_{23}{ }^{(6-x)-}$ & 936 & 884 & & 395 & 370 & \\
\hline & 2.0 & $\mathrm{H}_{x} \mathrm{P}_{2} \mathrm{Mo}_{5} \mathrm{O}_{23}{ }^{(6-x)-}$ & 942 & 893 & & 395 & 370 & \\
\hline
\end{tabular}

All impregnation solutions were prepared using appropriate amounts of $\left(\mathrm{NH}_{4}\right)_{4} \mathrm{Mo}_{7} \mathrm{O}_{24}{ }^{6-} \cdot 4 \mathrm{H}_{2} \mathrm{O}$ (Acros, p.a.). Impregnation was carried out with AHM solutions at a $\mathrm{pH}$ of 5.2 and 9.0, in the following referred to as Mo-pH5.2 and Mo-pH9.0. The pH of the latter solution was adjusted by addition of $\mathrm{NH}_{4} \mathrm{OH}$ solution (Lamers \& Pleuger, p.a.). A $\mathrm{Mo}-$ citrate solution with a Mo/citrate ratio of $1: 1$ and a $\mathrm{pH}$ of 0.5 was prepared using crystalline citric acid (OPG Farma, p.a.). Solutions with a Mo/P ratio of 2:1 and 1:1 were prepared using $85 \% \mathrm{H}_{3} \mathrm{PO}_{4}$ (Merck, p.a.). They are referred to as $\mathrm{Mo}-\mathrm{P}(0.5)$ and $\mathrm{Mo}-\mathrm{P}(1.0)$, respectively. The $\mathrm{pH}$ of the $\mathrm{Mo}-\mathrm{P}(1.0)$ solution was adjusted to a $\mathrm{pH}$ of 2 , the natural $\mathrm{pH}$ of the $\mathrm{Mo}-\mathrm{P}(0.5)$ solution, by addition of $\mathrm{NH}_{4} \mathrm{OH}$ solution. The chemical composition of the different solutions used is given in Table 1. Reference solutions of different $\mathrm{pH}$ 's were prepared for the different systems with concentrations of $1 \mathrm{M} \mathrm{Mo,} 1 \mathrm{M} \mathrm{Mo/0.5} \mathrm{M} \mathrm{P,}$ and $1 \mathrm{M} \mathrm{Mo} / 1 \mathrm{M}$ citrate, respectively. The composition of these solutions was calculated as a function of $\mathrm{pH}$, making use of a computer program, which contains equilibrium and formation constants for the different complexes. ${ }^{53,54}$

$\mathrm{NH}_{4} \mathrm{NO}_{3}$ (Acros, p.a.) was added to all solutions in a concentration of $0.66 \mathrm{M}$. In this way, the $\mathrm{NO}_{3}{ }^{-}$peak at $1048 \mathrm{~cm}^{-1}$ could be used as an internal standard in Raman measurements. To make sure that this method is valid during measurements on $\mathrm{Al}_{2} \mathrm{O}_{3}$ bodies after impregnation, a homogeneous distribution of $\mathrm{NO}_{3}{ }^{-}$throughout the support is a prerequisite. This was verified by impregnating the $\mathrm{Al}_{2} \mathrm{O}_{3}$ pellets with a $0.66 \mathrm{M} \mathrm{NH}_{4} \mathrm{NO}_{3}$ solution of $\mathrm{pH} 1$. Already after $10 \mathrm{~min}$, a homogeneous distribution of $\mathrm{NO}_{3}{ }^{-}$was found, judging from the constant intensity of the peak at $1048 \mathrm{~cm}^{-1}$ after scaling to the $\mathrm{Al}_{2} \mathrm{O}_{3}$ background. From this, it can be concluded that transport of $\mathrm{NO}_{3}{ }^{-}$through the pores of the support is fast and there is no noticeable interaction between $\mathrm{NO}_{3}{ }^{-}$ions and the $\mathrm{Al}_{2} \mathrm{O}_{3}$ surface. An even distribution of $\mathrm{NO}_{3}{ }^{-}$may therefore be assumed. Hence, the $\mathrm{NO}_{3}{ }^{-}$peak at $1048 \mathrm{~cm}^{-1}$ can be used as an internal standard.

\section{Results}

1. Raman Spectroscopy on Reference Solutions. A. Mo Solutions. Figure 1 shows the Raman spectra and the Mo speciation as a function of the solution $\mathrm{pH}$ for several reference solutions. According to the Mo speciation calculations, $\mathrm{Mo}_{7} \mathrm{O}_{24}{ }^{6-}$ will be mainly present in $1 \mathrm{M}$ AHM solutions at $\mathrm{pH}$ 5.5. The Raman spectrum of $\mathrm{Mo}_{7} \mathrm{O}_{24}{ }^{6-}$ shows peaks at $941 \mathrm{~cm}^{-1}\left(v_{\mathrm{s}}\right.$ $\left.\mathrm{MoO}_{2 \mathrm{t}}\right), 896 \mathrm{~cm}^{-1}\left(v_{\mathrm{as}} \mathrm{MoO}_{2 \mathrm{t}}\right)$, and $358 \mathrm{~cm}^{-1}\left(\delta \mathrm{MoO}_{2 \mathrm{t}}\right)$ in accordance with literature. ${ }^{40}$ Characteristic vibrations of all Mo complexes used in this study are presented in Table 2. At higher $\mathrm{pH}$, formation of $\mathrm{MoO}_{4}{ }^{2-}$ occurs according to eq $1 . \mathrm{MoO}_{4}{ }^{2-}$ shows characteristic vibrational bands at $896 \mathrm{~cm}^{-1}\left(\nu_{\mathrm{s}} \mathrm{MoO}_{2 \mathrm{t}}\right)$, $836 \mathrm{~cm}^{-1}\left(v_{\mathrm{as}} \mathrm{MoO}_{2 \mathrm{t}}\right)$, and $320 \mathrm{~cm}^{-1}\left(\delta \mathrm{MoO}_{2 \mathrm{t}}\right)$. At $\mathrm{pH} 8$ and higher, only $\mathrm{MoO}_{4}{ }^{2-}$ is present in solution.

$$
7 \mathrm{MoO}_{4}{ }^{2-}+8 \mathrm{H}^{+} \leftrightarrow \mathrm{Mo}_{7} \mathrm{O}_{24}{ }^{6-}+4 \mathrm{H}_{2} \mathrm{O}
$$

(53) Pettersson, L.; Andersson, I.; Öhman, L.-O. Inorg. Chem. 1986, 25, 47264733

(54) Cruywagen, J. J.; Rohwer, E. A.; Wessels, G. F. S. Polyhedron 1995, 14, $3481-3493$. 
Mo-pH 9.0
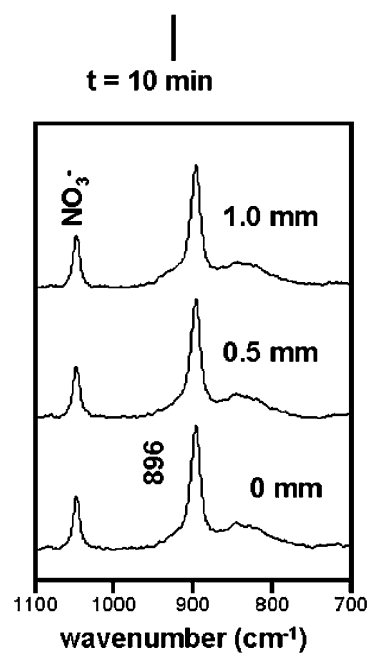

\section{Mo-pH 5.2}

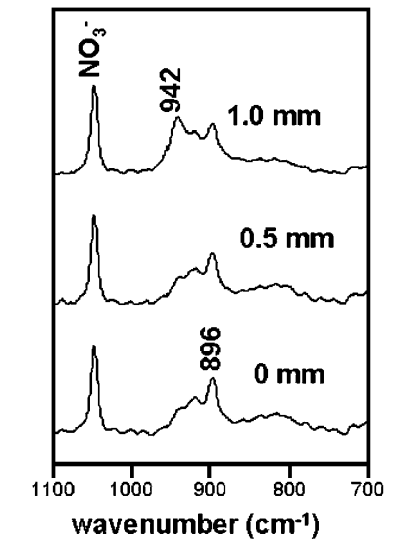

$t=240 \min$

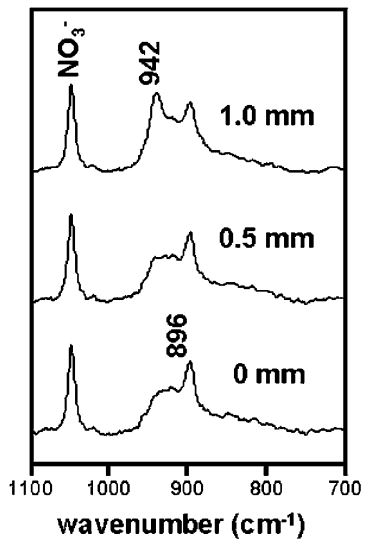

$\mathbf{t}=\mathbf{2 4} \mathrm{hrs}$

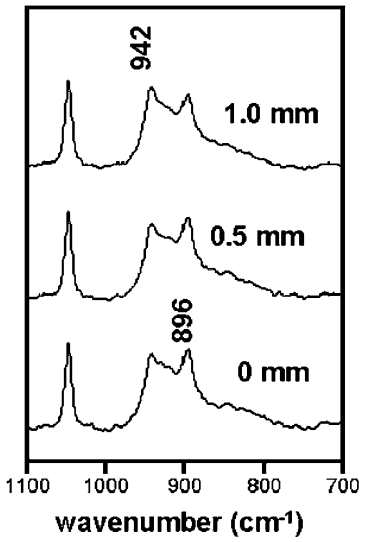

Figure 2. Raman spectra of catalyst support bodies impregnated with AHM solutions of different $\mathrm{pH}$. The Raman laser was focused $0,0.5$, and $1.0 \mathrm{~mm}$ from the center. Spectra were recorded $10 \mathrm{~min}$ after impregnation with a Mo-pH 9.0 solution and $30 \mathrm{~min}, 240 \mathrm{~min}$, and $24 \mathrm{~h}$ after impregnation with a Mo-pH 5.2 solution.

B. Mo-Citrate Solutions. In a 1:1 Mo-citrate solution, the $\mathrm{Mo}_{4}(\text { Hcitrate })_{2} \mathrm{O}_{11}{ }^{4-}$ complex is the stable species at $\mathrm{pH} 0.5-$ 2.0. Its Raman spectrum shows bands at 944 and $901 \mathrm{~cm}^{-1}$ and a small peak at $861 \mathrm{~cm}^{-1}$, which seems to be diagnostic for any $\mathrm{Mo}$-citrate complex. The $\delta\left(\mathrm{MoO}_{2 \mathrm{t}}\right)$ vibrations are found at 385,373 , and $343 \mathrm{~cm}^{-1}$. At higher $\mathrm{pH}$, the formation of $\mathrm{Mo}$ (Hcitrate) $\mathrm{O}_{3}{ }^{3-}$ complex will be favored as is obvious from eq 2. In addition, higher concentrations of citrate will also favor the formation of the 1:1 Mo-citrate complex. At higher $\mathrm{pH}$ deprotonation of the free carboxyl group of the citrate will take place. $\mathrm{Mo}\left(\mathrm{H}_{x}\right.$ citrate $) \mathrm{O}_{3}{ }^{(4-x)-}$ can be recognized by the $v\left(\mathrm{MoO}_{2 \mathrm{t}}\right)$ bands at 933,901 , and $861 \mathrm{~cm}^{-1}$ and $\delta\left(\mathrm{MoO}_{2 \mathrm{t}}\right)$ vibration at $385 \mathrm{~cm}^{-1}, 55$ irrespective of the protonation state of the citrate ligand. Eventually, $\mathrm{MoO}_{4}{ }^{2-}$ will be formed at $\mathrm{pH} \geq 8.5$ as eq 3 proceeds to the left.

$$
\begin{aligned}
& \begin{array}{l}
4 \mathrm{Mo}(\text { Hcitrate }) \mathrm{O}_{3}{ }^{3-}+8 \mathrm{H}^{+} \leftrightarrow \\
\mathrm{Mo}_{4}(\text { Hcitrate })_{2} \mathrm{O}_{11}{ }^{4-}+2 \mathrm{H}_{4} \text { citrate }+\mathrm{H}_{2} \mathrm{O}
\end{array} \\
& \mathrm{MoO}_{4}{ }^{2-}+\mathrm{Hcitrate}^{3-}+\mathrm{H}^{+} \leftrightarrow \\
& \\
& \quad \mathrm{Mo}(\text { citrate }) \mathrm{O}_{3}{ }^{4-}+\mathrm{H}_{2} \mathrm{O}
\end{aligned}
$$

C. Mo-P Solutions. Our calculations indicate that only $\mathrm{H}_{x} \mathrm{P}_{2} \mathrm{Mo}_{5} \mathrm{O}_{23}{ }^{(6-x)-}$ complexes will be formed in acidic solutions at $\mathrm{Mo} / \mathrm{P}$ ratios of $2: 1$ and $1: 1$. The $\mathrm{H}_{x} \mathrm{P}_{2} \mathrm{Mo}_{5} \mathrm{O}_{23}{ }^{(6-x)-}$ complex is stable in different protonation states over a wide $\mathrm{pH}$ range. Characteristic Raman peaks in the corresponding Raman spectra (Figure 1) can be found at 370 and $395 \mathrm{~cm}^{-1}\left(\delta\left(\mathrm{MoO}_{2 \mathrm{t}}\right)\right)$. At $\mathrm{pH} 2.0$ the $v_{\mathrm{s}}\left(\mathrm{MoO}_{2 \mathrm{t}}\right)$ and $v_{\mathrm{as}}\left(\mathrm{MoO}_{2 \mathrm{t}}\right)$ vibrations of the $\mathrm{H}_{x} \mathrm{P}_{2} \mathrm{Mo}_{5} \mathrm{O}_{23}{ }^{(6-x)-}$ complex are found at $942 \mathrm{~cm}^{-1}$ and $893 \mathrm{~cm}^{-1}$, respectively. These bands shift to lower frequency upon deprotonation. The $\mathrm{P}_{2} \mathrm{Mo}_{5} \mathrm{O}_{23}{ }^{6-}$ complex, present in solution at $\mathrm{pH} 6$, shows bands at 956, 926, and $874 \mathrm{~cm}^{-1}$. In basic solutions, all Mo will again be present as $\mathrm{MoO}_{4}{ }^{2-}$, as the equilibrium shifts to the left according to eq 4 .

$$
\begin{aligned}
& 5 \mathrm{MoO}_{4}{ }^{2-}+2 \mathrm{PO}_{4}^{3-}+10 \mathrm{H}^{+} \leftrightarrow \\
& \mathrm{P}_{2} \mathrm{Mo}_{5} \mathrm{O}_{23}{ }^{6-}+5 \mathrm{H}_{2} \mathrm{O}
\end{aligned}
$$

2. Raman Spectroscopy on the Cross Section of Impregnated Support Bodies. A. Mo Solutions. Figure 2 shows the Raman spectra taken at three positions along the diameter of the support bodies $10 \mathrm{~min}$ after impregnation with a Mo-pH 9.0 solution. The values that are indicated in the figure represent the distance from the core of the pellet. In all spectra, only peaks at 896,836 , and $320 \mathrm{~cm}^{-1}$ are present, characteristic of $\mathrm{MoO}_{4}{ }^{2-}$ in solution (Table 2). The intensity of the $v\left(\mathrm{MoO}_{2 \mathrm{t}}\right)$ peaks compared to the $\mathrm{NO}_{3}{ }^{-}$peak serves as an indication of the concentration of Mo in the solution present in the pores of the support. After comparison to the spectra of the reference solutions, as represented in Figure 1, an indication of the amount of Mo that has penetrated the support bodies can be obtained. In this case, it can be concluded that a homogeneous distribution of this anion is obtained throughout the support, as the Mo concentration of the solution inside the pores of the support is similar to that of the impregnation solution.

Raman spectra of the interior of pellets impregnated with a Mo-pH 5.2 solution are also presented in Figure 2. Spectra were recorded after $30 \mathrm{~min}, 240 \mathrm{~min}$, and $24 \mathrm{~h}$. From the intensity of the peaks it can be concluded that, in this case, the Mo concentration on the inside of the support bodies is much lower than in the Mo-pH5.2 solution used for impregnation. After 30 min, Mo is predominantly present as $\mathrm{MoO}_{4}{ }^{2-}$ near the core of the pellets, as can be concluded from the $v\left(\mathrm{MoO}_{2 \mathrm{t}}\right)$ vibration at $896 \mathrm{~cm}^{-1}$. An additional feature is observed at $920 \mathrm{~cm}^{-1}$. This peak cannot be observed in any Mo solution and must therefore be attributed to a Mo species in interaction with the $\mathrm{Al}_{2} \mathrm{O}_{3}$ support. In literature, it is ascribed to some form of tetrahedrally surrounded Mo adsorbed onto the support. ${ }^{40}$ Near the edge of the pellets, a $v\left(\mathrm{MoO}_{2 \mathrm{t}}\right)$ vibration is observed at $942 \mathrm{~cm}^{-1}$ pointing to the presence of $\mathrm{Mo}_{7} \mathrm{O}_{24}{ }^{6-}$ (Table 2). In time, $\mathrm{Mo}_{7} \mathrm{O}_{24}{ }^{6-}$ is also observed near the center of the support bodies. After impregnation ( $24 \mathrm{~h}$ ), the spectrum recorded near the core of the support body is similar to that recorded near the edge and $\mathrm{MoO}_{4}{ }^{2-}$ and $\mathrm{Mo}_{7} \mathrm{O}_{24}{ }^{6-}$ are present in the same amount throughout the pellets.

B. Mo-Citrate Solution. All Raman spectra of the support bodies impregnated with a Mo-citrate 1:1 solutions show only 

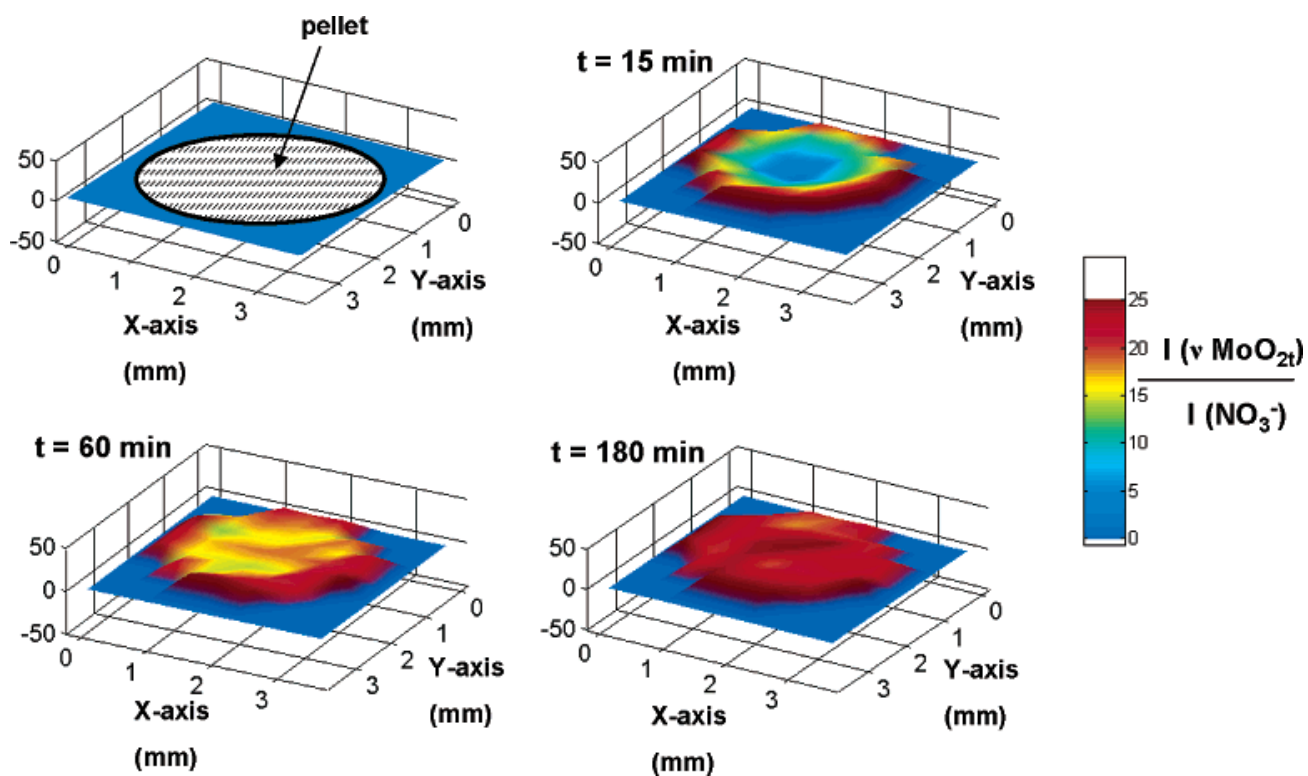

Figure 3. Three-dimensional plots illustrating the spatial distribution of the $\mathrm{Mo}_{4}(\text { Hcitrate })_{2} \mathrm{O}_{11}{ }^{4-}$ complex in $3 \mathrm{~mm} \mathrm{Al}_{2} \mathrm{O}_{3}$ pellets 15 , 60 , and 180 min after impregnation with a $\mathrm{Mo}-$ citrate solution. The intensity plots are obtained by referencing to the $\mathrm{NO}_{3}{ }^{-}$Raman band.
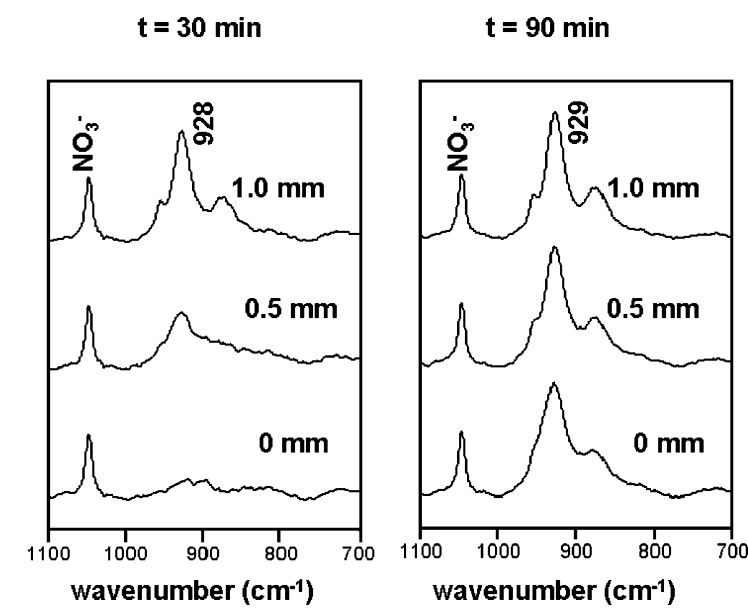

\section{$\mathrm{t}=\mathbf{3 6 0} \mathrm{min}$}

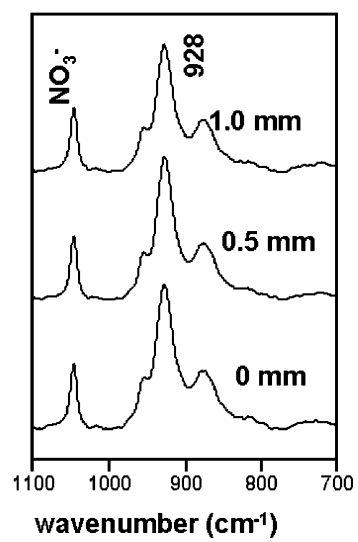

Figure 4. Raman spectra of catalyst bodies impregnated with a Mo-P(1.0) solution. The Raman laser was focused $0,0.5$, and $1.0 \mathrm{~mm}$ from the center. Spectra were recorded 30, 90, and 360 min after impregnation.

the characteristic $v\left(\mathrm{MoO}_{2 \mathrm{t}}\right)$ vibrations of the $\mathrm{Mo}_{4}(\text { Hcitrate })_{2} \mathrm{O}_{11}{ }^{4-}$ at 944, 901, and $861 \mathrm{~cm}^{-1}$ (Table 2). As $\mathrm{Mo}_{4}\left(\right.$ Hcitrate) ${ }_{2} \mathrm{O}_{11}{ }^{4-}$ is the only Mo complex present, an estimate of its amount can be obtained by taking the ratio of the area of the $v\left(\mathrm{MoO}_{2 \mathrm{t}}\right)$ (integration width: $840-970 \mathrm{~cm}^{-1}$ ) and the area of the $\mathrm{NO}_{3}{ }^{-}$ (integration width: $1038-1058 \mathrm{~cm}^{-1}$ ) Raman bands. In this way, a distribution profile of the $\mathrm{Mo}_{4}(\text { Hcitrate })_{2} \mathrm{O}_{11}{ }^{4-}$ complex over the cross section of the catalyst bodies may be obtained at different times after impregnation. In Figure 3, the distribution of the complex over the profile of an $\mathrm{Al}_{2} \mathrm{O}_{3}$ pellet is illustrated in a three-dimensional plot at 15, 60, and $180 \mathrm{~min}$ after impregnation. From these plots, it is clear that a radial distribution of the Mo complex is established at all times. In this way, the use of cross-sectional scans as a faster way to monitor the distribution of Mo complexes throughout the pellets is validated. The $\mathrm{Mo}_{4}(\text { Hcitrate })_{2} \mathrm{O}_{11}{ }^{4-}$ concentration gradient over the support bodies decreases as a function of time. A reasonably homogeneous distribution of the complex is reached $180 \mathrm{~min}$ after impregnation.

C. Mo-P Solutions. In Figure 4, Raman spectra recorded along the diameter of the interior of support bodies are presented
30, 90, and $360 \mathrm{~min}$ after impregnation with a Mo-P(1.0) solution. At $30 \mathrm{~min}$ after impregnation, $v\left(\mathrm{MoO}_{2 \mathrm{t}}\right)$ peaks at 956 , 928 , and $878 \mathrm{~cm}^{-1}$ are observed near the edge of the pellets. The $\delta\left(\mathrm{MoO}_{2 \mathrm{t}}\right)$ vibrations at 370 and $395 \mathrm{~cm}^{-1}$ that are observed reveal that Mo is present as a $\mathrm{H}_{x} \mathrm{P}_{2} \mathrm{Mo}_{5} \mathrm{O}_{23}{ }^{(6-x)-}$ heteropolyanion (Table 2). At the same time, hardly any Mo complexes are observed near the core of the catalyst bodies. At 90 min after impregnation, $\delta\left(\mathrm{MoO}_{2 \mathrm{t}}\right)$ vibrations at 370 and $395 \mathrm{~cm}^{-1}$ are observed over the entire profile, indicating the presence of $\mathrm{H}_{x} \mathrm{P}_{2} \mathrm{Mo}_{5} \mathrm{O}_{23}{ }^{(6-x)-}$ throughout the support bodies (Table 2). The main $v\left(\mathrm{MoO}_{2 \mathrm{t}}\right)$ vibration is observed at $929 \mathrm{~cm}^{-1}$ for all positions inside the alumina support. Near the core, a slightly higher Raman intensity is observed at 935-940 $\mathrm{cm}^{-1}$. A reasonably homogeneous distribution of Mo complexes can be assumed from the relative intensity of the $v\left(\mathrm{MoO}_{2 \mathrm{t}}\right)$ vibrations. After $360 \mathrm{~min}$, the feature at $935-940 \mathrm{~cm}^{-1}$ has disappeared, and identical Raman spectra are recorded over the entire cross section.

Figure 5 shows the Raman spectra recorded along the diameter of the interior of the catalyst bodies 30, 90, and 360 min after impregnation with a $\mathrm{Mo}-\mathrm{P}(0.5)$ solution. No $v\left(\mathrm{MoO}_{2 \mathrm{t}}\right)$ 
$\mathbf{t}=\mathbf{3 0} \mathrm{min}$

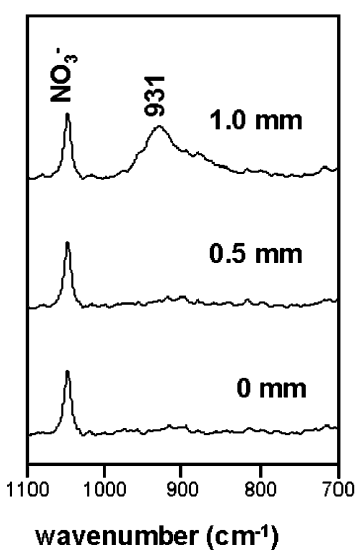

$\mathbf{t}=90 \mathrm{~min}$

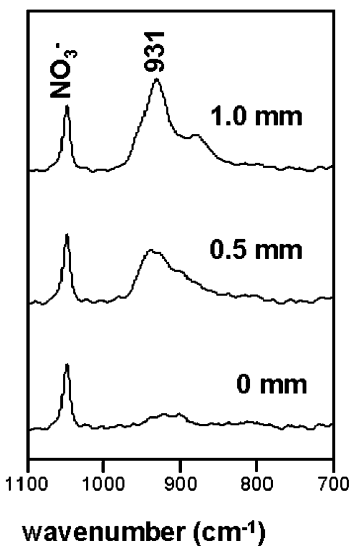

$t=360 \min$

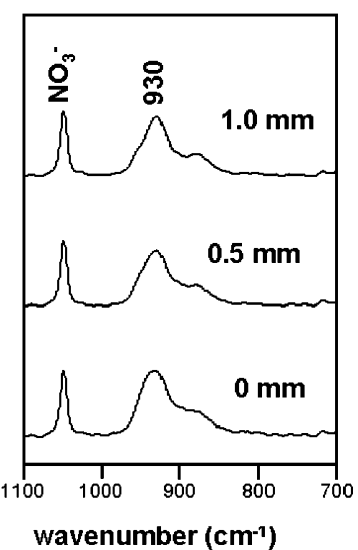

Figure 5. Raman spectra of catalyst bodies impregnated with a Mo-P(0.5) solution. The Raman laser was focused $0,0.5$, and $1.0 \mathrm{~mm}$ from the center. Spectra were recorded 30,90 , and 360 min after impregnation.

AHM solutions

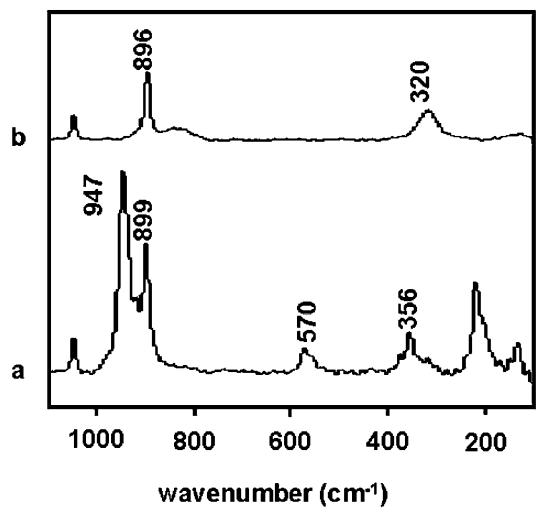

Mo-P(1.0) solution

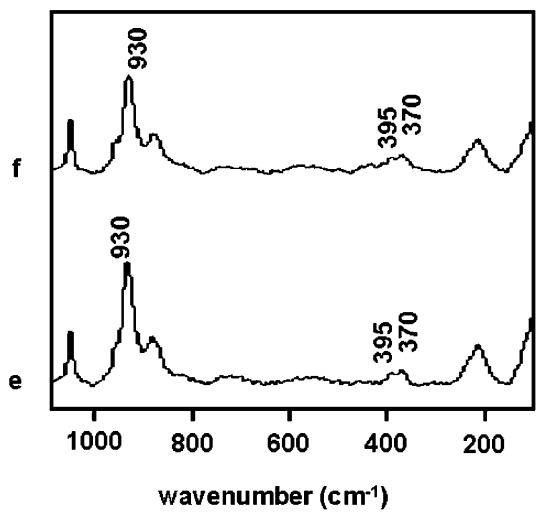

Mo-citrate solution

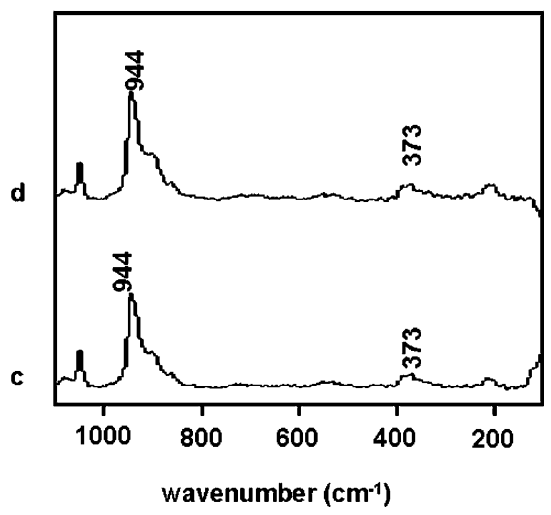

Mo-P(0.5) solution

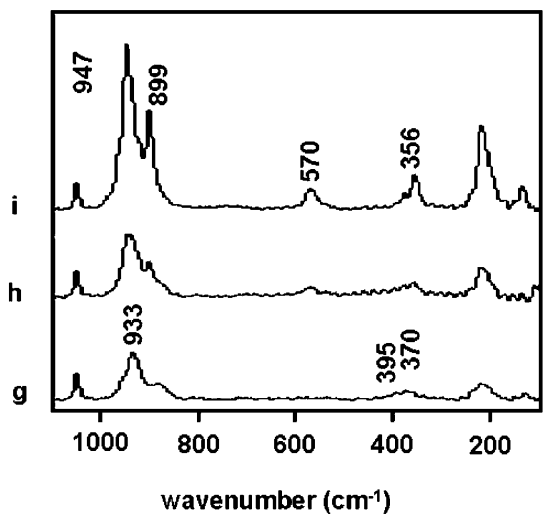

Figure 6. Raman spectra recorded of the external surface of catalyst bodies impregnated with a Mo-pH 5.2 solution after 30 min (a), Mo-pH 9.0 solution after $45 \mathrm{~min}(\mathrm{~b}), \mathrm{Mo}$ - citrate solution after $120 \mathrm{~min}$ (c) and $240 \mathrm{~min}(\mathrm{~d}), \mathrm{Mo}-\mathrm{P}(1.0)$ solution after $45 \mathrm{~min}$ (e) and $360 \mathrm{~min}(\mathrm{f})$, and $\mathrm{Mo}-\mathrm{P}(0.5)$ solution after $40 \mathrm{~min}(\mathrm{~g}), 180 \mathrm{~min}(\mathrm{~h})$, and $300 \mathrm{~min}(\mathrm{i})$.

peaks are observed on the inner part of the pellets after $30 \mathrm{~min}$. Near the edge, a broad $v\left(\mathrm{MoO}_{2 \mathrm{t}}\right)$ peak is observed with a maximum at $931 \mathrm{~cm}^{-1}$. After $360 \mathrm{~min}$, Mo complexes are present throughout the profile of the support bodies. However, from the intensity ratio of the $v\left(\mathrm{MoO}_{2 \mathrm{t}}\right)$ and $\mathrm{NO}_{3}{ }^{-}$peaks, it is clear that the loading is considerably lower than what could be assumed from the concentration in the impregnation solution that was used. The maximum is found at $930 \mathrm{~cm}^{-1}$ at all positions, with a shoulder at $940 \mathrm{~cm}^{-1}$ observed near the core of the pellets. The $\delta\left(\mathrm{MoO}_{2 \mathrm{t}}\right)$ vibrations at 370 and $395 \mathrm{~cm}^{-1}$ indicate that Mo is predominantly present as $\mathrm{H}_{x} \mathrm{P}_{2} \mathrm{Mo}_{5} \mathrm{O}_{23}{ }^{(6-x)-}$ in all cases (Table 2).

3. Raman Spectroscopy on the Outer Surface of Support Bodies. Raman spectra recorded at the exterior of the catalyst bodies impregnated with different Mo solutions are presented in Figure 6. Again, after impregnation with a Mo-pH 9.0 solution, only Raman peaks corresponding to $\mathrm{MoO}_{4}{ }^{2-}$ are observed at 896,836 , and $320 \mathrm{~cm}^{-1}$ (Table 2). After impregnation with a Mo-pH 5.2 solution, intense Raman peaks are observed at $947,899,570$, and $356 \mathrm{~cm}^{-1}$. In the literature, they 
are ascribed to the formation of $\mathrm{Al}(\mathrm{OH})_{6} \mathrm{Mo}_{6} \mathrm{O}_{18}{ }^{3-}$, an Andersontype heteropolyanion. ${ }^{28,51}$ The peak at $570 \mathrm{~cm}^{-1}$ is generally regarded to originate from a $v(\mathrm{Al}-\mathrm{O})$ vibration. ${ }^{51}$ After impregnation with a Mo-citrate solution, the Raman spectrum of $\mathrm{Mo}_{4}$ (citrate) $)_{2} \mathrm{O}_{11}{ }^{4-}$ with peaks at $944,901,861$, and $373 \mathrm{~cm}^{-1}$ is observed at all times on the exterior surface. $\mathrm{H}_{x} \mathrm{P}_{2} \mathrm{Mo}_{5} \mathrm{O}_{23}{ }^{(6-x)-}$ is the only species on the outside of pellets impregnated with a Mo-P(1.0) solution, yielding a Raman spectrum with characteristic vibrations at $955,930,878,395$, and $370 \mathrm{~cm}^{-1}$. During the first $90 \mathrm{~min}$ after impregnation with a $\mathrm{Mo}-\mathrm{P}(0.5)$ solution, $\mathrm{H}_{x} \mathrm{P}_{2} \mathrm{Mo}_{5} \mathrm{O}_{23}{ }^{(6-x)-}$ is the only observed Mo species. After 180 min, the formation of $\mathrm{Al}(\mathrm{OH})_{6} \mathrm{Mo}_{6} \mathrm{O}_{18}{ }^{3-}$ is observed, and after $300 \mathrm{~min}$, this compound seems to be present in large amounts on the outer surface of the support bodies.

\section{Discussion}

1. Physicochemical Processes in Catalyst Bodies after Impregnation. A. Mo Solutions. Impregnation with a Mo-pH 9.0 solution results in a homogeneous distribution of $\mathrm{MoO}_{4}{ }^{2-}$ throughout the support bodies within $10 \mathrm{~min}$ (Figure 2). As the $\mathrm{pH}$ of the impregnation solution is close to the PZC of alumina, the surface charge of the support is nil and interaction between the $\mathrm{Al}_{2} \mathrm{O}_{3}$ surface and the $\mathrm{MoO}_{4}{ }^{2-}$ anions solution is not significant. ${ }^{56}$ Not hampered by adsorption, the $\mathrm{MoO}_{4}{ }^{2-}$ anions will travel with the convective flow of the water phase, and fast transport of the complex through the pores of the support can take place. As there is little interaction with the support, the spectrum of $\mathrm{MoO}_{4}{ }^{2-}$ observed in the freshly prepared catalyst is identical to that of the same compound in solution.

On the contrary, impregnation with a Mo-pH5.2 solution results in slow transport of Mo anions through the pores of the support (Figure 2), as a result of adsorption of Mo anions onto the $\mathrm{Al}_{2} \mathrm{O}_{3}$ surface. Interaction between the $\mathrm{Al}_{2} \mathrm{O}_{3}$ support and Mo anions in solution can take place according to eq 5.45 This reaction is facilitated by the lower $\mathrm{pH}$ of this impregnation solution. As a consequence of this interaction between the anions in solution and the surface of the support, transport of the anions will be slow. Water will be distributed rapidly throughout the support, due to the viscous flow that results from the capillary forces. Consequently, in the first period after impregnation, the Mo concentration is very high at the external surface of the extrudates

$$
2 \mathrm{Al}_{\mathrm{s}} \mathrm{OH}+\mathrm{MoO}_{4}^{2-} \leftrightarrow\left(\mathrm{Al}_{\mathrm{s}}\right)_{2} \mathrm{MoO}_{4}+2 \mathrm{OH}^{-}
$$

In accordance with eq 5, the adsorption of $\mathrm{MoO}_{4}{ }^{2-}$ is accompanied with an increase in $\mathrm{pH}$ inside the pores of the $\mathrm{Al}_{2} \mathrm{O}_{3}$. As a result, the equilibrium in eq 1 will shift to the left, and more $\mathrm{MoO}_{4}{ }^{2-}$ will be formed. Hence, as the Mo front travels through the support, $\mathrm{Mo}_{7} \mathrm{O}_{24}{ }^{6-}$ will be converted into free and adsorbed $\mathrm{MoO}_{4}{ }^{2-}$. Near the center of the pellets, only these species are indeed observed in the first hours after impregnation. After titration of all basic hydroxyls with $\mathrm{MoO}_{4}{ }^{2-}, \mathrm{Mo}_{7} \mathrm{O}_{24}{ }^{6-}$ can be stable inside the pores of the alumina support. In time, $\mathrm{Mo}_{7} \mathrm{O}_{24}{ }^{6-}$ can therefore diffuse toward the core of the pellets without disintegration. Electrostatic adsorption of $\mathrm{Mo}_{7} \mathrm{O}_{24}{ }^{6-}$ entities is reported to occur on coordinatively unsaturated $\mathrm{Al}^{3+}$ sites of an $\mathrm{Al}_{2} \mathrm{O}_{3}$ surface. ${ }^{45}$ The fact that the position of its

(55) Murase, K.; Ando, H.; Matsubara, E.; Hirato, T.; Awakura, Y. J. Electrochem. Soc. 2000, 147, 2210-2217.

(56) Park, J.; Regalbuto, J. R. J. Colloid Interface Sci. 1995, 175, 239-252.
$v\left(\mathrm{MoO}_{2 \mathrm{t}}\right)$ peak has not changed as compared to the impregnation solution indicates that only a Coulombic interaction exists between this complex and the support.

Finally, formation of the $\mathrm{Al}(\mathrm{OH})_{6} \mathrm{Mo}_{6} \mathrm{O}_{18}{ }^{3-}$ Anderson-type heteropolyanion, due to ligand-promoted dissolution of the $\mathrm{Al}_{2} \mathrm{O}_{3}$ support, is often observed when impregnation with an acidic AHM solution is carried out. ${ }^{28}$ Formation of this complex is reported to take place in an acidic environment where hydrated $\mathrm{Al}^{3+}$ ions react with $\mathrm{MoO}_{4}{ }^{2-}$ in solution in accordance with eq 6.

$$
6 \mathrm{MoO}_{4}{ }^{2-}+\mathrm{Al}^{3+}+6 \mathrm{H}^{+} \leftrightarrow \mathrm{Al}(\mathrm{OH})_{6} \mathrm{Mo}_{6} \mathrm{O}_{18}{ }^{3-}
$$

Formation of $\mathrm{Al}(\mathrm{OH})_{6} \mathrm{Mo}_{6} \mathrm{O}_{18}{ }^{3-}$ is observed on the outside of the pellets, probably due to both the high local Mo concentration and the favorable $\mathrm{pH}$. As the solubility of $\mathrm{Al}(\mathrm{OH})_{6} \mathrm{Mo}_{6} \mathrm{O}_{18}{ }^{3-}$ is low, precipitation of this species will instantly take place. Large clusters of this compound will thus be formed on the outside of the support bodies in which a considerable amount of the Mo that is present in the system will be contained. For this reason, the Mo concentration inside the pellets is found to be low, as can be seen from the relative intensity ratio of the $v\left(\mathrm{MoO}_{2 \mathrm{t}}\right)$ and $\mathrm{NO}_{3}{ }^{-}$peaks (Figures 1 and $2)$. It is important to stress here that the formation of the $\mathrm{Al}(\mathrm{OH})_{6} \mathrm{Mo}_{6} \mathrm{O}_{18}{ }^{3-}$ compound is detrimental to the activity of the final catalyst as calcination of this compound will result in the formation of $\mathrm{MoO}_{3}$ clusters. ${ }^{43}$

B. Mo-Citrate Solution. After impregnation with a solution of $\mathrm{Mo}_{4}$ (Hcitrate $)_{2} \mathrm{O}_{11},{ }^{4-}$ a very slow transport of this complex is observed through the pores of the support, until finally a homogeneous distribution is obtained $180 \mathrm{~min}$ after impregnation (Figure 3). Diffusion is slower than that for the $\mathrm{MoO}_{4}{ }^{2-}$ species in the case of Mo-pH 9.0 and Mo-pH 5.2 solutions, as there will be a considerable electrostatic interaction between the positively charged support surface and the $\mathrm{Mo}_{4}(\text { Hcitrate })_{2} \mathrm{O}_{11}{ }^{4-}$ complex, due to the low $\mathrm{pH}$ of the impregnation solution. ${ }^{56} \mathrm{It}$ can be expected that protonation of the surface hydroxyl groups will result in an increase of the $\mathrm{pH}$ of the impregnation solution inside the pores of the support. Formation of $\mathrm{Mo}($ Hcitrate $) \mathrm{O}_{3}{ }^{3-}$ might then be expected, as the equilibrium in eq 2 is shifted to the right. However, this complex is not observed at any moment after impregnation. Apparently, the $\mathrm{pH}$ of the impregnation solution is sufficiently low to counteract the buffering influence of the support. Immediately after impregnation, the Mo concentration will be extremely high near the edges of the support bodies. Nevertheless, precipitation of Mo compounds is avoided as the solubility of $\mathrm{Mo}^{6+}$ is greatly enhanced due to the complexing ability of the citrate ligands.

C. Mo-P Solutions. When a molar ratio of Mo/P 1:1 or 2:1 is used in the impregnation solution, excess $\mathrm{H}_{x} \mathrm{PO}_{4}{ }^{(3-x)-}$ will be present as only $40 \%$ and $90 \%$ of the phosphorus will, respectively, be contained in the $\mathrm{H}_{x} \mathrm{P}_{2} \mathrm{Mo}_{5} \mathrm{O}_{23}{ }^{(6-x)-}$ complexes. This free phosphate is known to react with the hydroxyl groups of the $\mathrm{Al}_{2} \mathrm{O}_{3}$ support to form an amorphous $\mathrm{AlPO}_{4}$ layer, ${ }^{57,58}$ as indicated by eq 7. This reaction leads to a decrease in the free phosphate concentration and an increase in $\mathrm{pH}$ of the solution inside the pores of the support. As a result, the stability of the $\mathrm{H}_{x} \mathrm{P}_{2} \mathrm{Mo}_{5} \mathrm{O}_{23}{ }^{(6-x)-}$ will be decreased, as the equilibrium

(57) Kraus, H.; Prins, R. J. Catal. 1996, 164, 251-259.

(58) Kraus, H.; Prins, R. J. Catal. 1997, 170, 20-28. 
in eq 8 is shifted to the right. The free phosphate, which is formed upon disintegration of $\mathrm{H}_{x} \mathrm{P}_{2} \mathrm{Mo}_{5} \mathrm{O}_{23}{ }^{(6-x)-}$, is again available for reaction with the support, speeding up this reaction cycle. Finally, an equilibrium state will be reached in which the phosphate concentration in the impregnation solution determines the stability of the $\mathrm{H}_{x} \mathrm{P}_{2} \mathrm{Mo}_{5} \mathrm{O}_{23}{ }^{(6-x)}{ }^{-}$inside the pores of the support. This is in accordance with literature, in which it is stated that interaction of $\mathrm{H}_{x} \mathrm{P}_{2} \mathrm{Mo}_{5} \mathrm{O}_{23}{ }^{(6-x)-}$ with the hydroxyl groups of the $\mathrm{Al}_{2} \mathrm{O}_{3}$ supports will result in the disintegration of the complex, when no excess free phosphate is present. ${ }^{44,46}$ It is also reported that physisorption of $\mathrm{H}_{x} \mathrm{P}_{2} \mathrm{Mo}_{5} \mathrm{O}_{23}{ }^{(6-x)-}$ and $\mathrm{Mo}_{7} \mathrm{O}_{24}{ }^{6-}$ can take place on the $\mathrm{AlPO}_{4}$ layer that has been formed. ${ }^{46}$

$$
\begin{gathered}
\mathrm{Al}_{\mathrm{s}} \mathrm{OH}+\mathrm{HPO}_{4}{ }^{2-}+\mathrm{H}^{+} \leftrightarrow \mathrm{Al}_{\mathrm{s}} \mathrm{HPO}_{4}{ }^{-}+\mathrm{H}_{2} \mathrm{O} \\
7 \mathrm{P}_{2} \mathrm{Mo}_{5} \mathrm{O}_{23}{ }^{6-}+15 \mathrm{H}_{2} \mathrm{O} \leftrightarrow \\
5 \mathrm{Mo}_{7} \mathrm{O}_{24}{ }^{6-}+14 \mathrm{HPO}_{4}{ }^{2-}+16 \mathrm{H}^{+}
\end{gathered}
$$

Impregnation with a $\mathrm{Mo}-\mathrm{P}(1.0)$ solution results in a reasonably homogeneous distribution of $\mathrm{H}_{x} \mathrm{P}_{2} \mathrm{Mo}_{5} \mathrm{O}_{23}{ }^{(6-x)-}$ throughout the support after $90 \mathrm{~min}$. Disintegration of the complex (eq 8) is prevented, as enough free phosphate is present. However, the reaction between free phosphate and the support is accompanied with an increase in the $\mathrm{pH}$ of the impregnation solution inside the pores of the support, as is obvious from eq 7. For this reason, the $v\left(\mathrm{MoO}_{2 \mathrm{t}}\right)$ vibration is shifted to lower frequency due to deprotonation of the $\mathrm{H}_{x} \mathrm{P}_{2} \mathrm{Mo}_{5} \mathrm{O}_{23}{ }^{(6-x)-}$ complex (Figure 4). From the position of the main $v\left(\mathrm{MoO}_{2 \mathrm{t}}\right)$ vibration band at $929 \mathrm{~cm}^{-1}$, it can be concluded that the $\mathrm{pH}$ of the solution in the pores of the $\mathrm{Al}_{2} \mathrm{O}_{3}$ is raised to a $\mathrm{pH}$ of about 5. Above the $\mathrm{AlPO}_{4}$ overlayer that is formed, $\mathrm{H}_{x} \mathrm{P}_{2} \mathrm{Mo}_{5} \mathrm{O}_{23}{ }^{(6-x)-}$ can be stable inside the pores of the support. Possibly, the diffusion of free phosphate somewhat lags behind that of the $\mathrm{H}_{x} \mathrm{P}_{2} \mathrm{Mo}_{5} \mathrm{O}_{23}{ }^{(6-x)-}$ complex. The feature at $935-945 \mathrm{~cm}^{-1}$, observed near the core of the pellets after 90 min, may then be explained by the formation of $\mathrm{Mo}_{7} \mathrm{O}_{24},{ }^{6-}$ as a result of a low local free phosphate concentration.

When impregnation is carried out with a Mo- $\mathrm{P}(0.5)$ solution, diffusion of Mo complexes is found to be slower and the amount of Mo that finally diffuses to the inside of the catalyst bodies is considerably lower. Not enough free phosphate is present in the impregnation solution to prevent disintegration of $\mathrm{H}_{x} \mathrm{P}_{2} \mathrm{Mo}_{5} \mathrm{O}_{23}{ }^{(6-x)-}$. $\mathrm{Mo}_{7} \mathrm{O}_{24}{ }^{6-}$ will therefore be formed. As was observed in the impregnation with a Mo-pH 5.2 solution, diffusion of $\mathrm{Mo}_{7} \mathrm{O}_{24}{ }^{6-}$ is a slow process. Hence, a high concentration of Mo is again established near the edge of the pellets. Reaction of the $\mathrm{Mo}_{7} \mathrm{O}_{24}{ }^{6-}$ species with dissolved $\mathrm{Al}^{3+}$ once again results in the formation of considerable amounts of $\mathrm{Al}(\mathrm{OH})_{6} \mathrm{Mo}_{6} \mathrm{O}_{18}{ }^{3-}$ on the outside of the catalyst bodies.

\section{Evaluation of the Time-Resolved Raman Microscopy}

Method. In former fundamental studies into the interaction between Mo anions and an $\mathrm{Al}_{2} \mathrm{O}_{3}$ support during catalyst preparation, characterization has predominantly been carried out on powder supports or on crushed extrudates. ${ }^{28,43-46,51}$ In this way, discrimination between processes occurring on the outer surface or in the pore system of particles is impossible. As was illustrated in this work, after the impregnation of support bodies, several physicochemical processes play a role that could not be monitored in these studies, due to this lack of spatial resolution. Moreover, as diffusion lengths will be short, adsorption and reaction of Mo complexes with the support are instantaneous, when impregnation is carried out on a powder support. During impregnation of support bodies, long diffusion lengths will act as a slow motion on the system, and the time and place dependency of different molybdenum oxide species yields additional information on their origin and formation.

As in industry impregnation is usually carried out on extrudates of millimeter scale, studies on powder supports are of limited value in large-scale catalyst preparation. In principle, Raman microscopy can easily be applied to study the Mo speciation of dried and calcined catalyst support bodies, although dehydration or even ignition of the sample may be a serious problem. Hence, the spatially resolved Raman method presented in this study can be used to monitor the distribution of Mo complexes over the catalyst bodies throughout their preparation process. This yields interesting opportunities for quality control in industrial catalyst preparation. Insight into the physicochemical processes that play a role during preparation of catalyst bodies allows for a more controlled preparation of industrial catalysts in the future.

Raman microscopy may easily be combined with other characterization techniques that can be applied in a spatially resolved mode, such as IR and UV-vis. IR microscopy, for instance, could be used to study the distribution of complexing agents. Application of UV-vis microscopy would make it possible to follow the distribution of $\mathrm{Co}$ and $\mathrm{Ni}$ complexes during preparation of Co- and Ni-promoted $\mathrm{MoS}_{2} / \mathrm{Al}_{2} \mathrm{O}_{3} \mathrm{HDS}$ catalysts. Both types of characterization work are in progress in our group. More in general, we believe that the proposed characterization method is very valuable and applicable to other supported catalysts as well.

\section{Conclusions}

The interaction between aqueous Mo complexes and $\mathrm{Al}_{2} \mathrm{O}_{3}$ can have severe consequences on the impregnation of millimeter-scale $\mathrm{Al}_{2} \mathrm{O}_{3}$ support bodies. A strong interaction between the Mo anions and the support will result in a slow transport of these compounds. As a result, the concentration of Mo complexes near the outer surface of the support bodies will be dramatically increased. For this reason, measures have to be taken to prevent precipitation of Mo complexes near the outer phase of the support bodies. A high concentration of Mo in combination with long contact times results in the formation of $\mathrm{Al}(\mathrm{OH})_{6} \mathrm{Mo}_{6} \mathrm{O}_{18}{ }^{3-}$ clusters, which will be converted into $\mathrm{MoO}_{3}$ upon calcination.

This unwanted process may be avoided in three ways. First of all, the interaction between the anions and the support can be diminished by choosing an impregnation solution with a $\mathrm{pH}$ that is larger than the PZC of the support. In this case, the anions will have no interaction with the neutral surface or slightly negatively charged surface, and diffusion will be fast. A homogeneous distribution of the anions will be established within minutes after impregnation, as was illustrated in this study by the impregnation with a Mo-pH 9.0 solution. However, a weak interaction between the metal precursor and the support could be a problem during drying, as the Mo complexes are not anchored to the support. The complex pore system of the support will result in the flow of impregnation solution and possibly agglomeration of Mo oxides. A second approach is to 
use agents that are able to form stable complexes with $\mathrm{Mo}^{6+}$. The solubility of Mo is enhanced, which will prevent precipitation, and its reactivity is decreased. In this way, formation of $\mathrm{Al}(\mathrm{OH})_{6} \mathrm{Mo}_{6} \mathrm{O}_{18}{ }^{3-}$ can be avoided. The use of organic ligands, such as citrate, yields the additional benefit that during drying a film is created on the surface of the support, which prevents agglomeration of Mo. ${ }^{59}$ Finally, reactive hydroxyl groups on the support can be titrated by reaction with an additional compound in the impregnation solution. A less reactive overlayer

(59) Van Dillen, A. J.; Terorde, R.; Lensveld, D. J.; Geus, J. W.; de Jong, K. P. J. Catal. 2003, 216, 257-264. is thus created, and diffusion of the Mo complexes will be faster. This is the case when phosphate in a $\mathrm{Mo}-\mathrm{P}$ solution reacts with the $\mathrm{Al}_{2} \mathrm{O}_{3}$ to form amorphous $\mathrm{AlPO}_{4}$. When a solution with sufficient free phosphate is used, a homogeneous distribution of $\mathrm{P}_{2} \mathrm{Mo}_{5} \mathrm{O}_{23}{ }^{6-}$ complexes is found within $120 \mathrm{~min}$ after impregnation.

Acknowledgment. B.M.W. acknowledges financial support by the Dutch National Science Foundation (NWO-CW-van der Leeuw and VICI grants), NRSC-Catalysis, and Albermarle Catalysts Company BV.

JA040107C 